Original research article

Section: Food Technology

\title{
Influence of Pretreatments on Microwave Vacuum Drying Kinetics, Physicochemical Properties and Sensory Quality of Apple Slices
}

\author{
Yingqiang Wang*, Hongxia Zhao, Huiwen Deng, Xi Song, Wenjie Zhang, Sirui Wu, Jing Wang \\ College of Agriculture and Forestry, Longdong University, 745000, Qingyang, China
}

Key words: apple slices, pretreatment, microwave vacuum drying, physicochemical properties, sensory quality

The objective of this study was to determine and compare the effect of five different pretreatments including sulfite treatment (ST), osmotic dehydration (OD), steam blanching (SB), steam blanching plus osmotic dehydration (SB+OD), and ultrasound treatment (UT), on the microwave vacuum drying (MVD) kinetics, the physicochemical properties, and sensory quality of the apple slices. The results showed that the pretreatments prior to MVD could reduce the drying time of apple slices by $25-45 \%$ as compared to the non-pretreated apple slices, and the drying time in the SB+OD apple slices sample was shortest. Whether pretreated or not, MVD process was controlled by diffusion and characterized by a two-stage falling-rate drying. As calculated according to the Fick's law of diffusion, the moisture diffusivities $\left(D_{e f f}\right)$ ranged from $1.64 \times 10^{-8}$ to $3.46 \times 10^{-8} \mathrm{~m}^{2} / \mathrm{s}$. Different pretreatment methods had a significant influence on the physicochemical properties and sensory qualities of the dried products $(p<0.05)$. The SB+OD-pretreated apple slices showed the lowest shrinkage (59.5\%) and the highest total sugar content ( $77.90 \mathrm{~g} / 100 \mathrm{~g}$ dry matter). Besides, the OD-pretreated apple slices showed the highest density $\left(0.953 \mathrm{~g} / \mathrm{cm}^{3}\right)$ and the lowest titratable acidity $(1.67 \mathrm{~g} / 100 \mathrm{~g}$ dry matter). In addition, the ST-pretreated samples showed the highest titratable acidity ( $3.21 \mathrm{~g} / 100 \mathrm{~g}$ dry matter) and vitamin C content $(12.74 \mathrm{mg} / 100 \mathrm{~g}$ dry matter), while the sample pretreated by SB showed the highest total phenolics content $(18.37 \mathrm{mg} / \mathrm{g}$ dry matter). Non-sulfite-pretreated samples were superior to the sulfite treatment or the control in flavor but inferior to the sulfite treatment in color. Results of preference sensory evaluation showed that the dried apple slices were preferred by the panelists in the following order: $\mathrm{SB}+\mathrm{OD}>\mathrm{SB}>\mathrm{UT}>\mathrm{OD}>\mathrm{ST}>$ the control.

\section{INTRODUCTION}

Apple, the most important temperate fruit of the world, is regarded as one of the most important raw material in the food industry and is processed into a variety of products such as juice, jam, marmalade, and variously dried products [Beigi, 2016]. China is the largest country in the world, which cultivates and consumes apples. According to the Food and Agriculture Organization (FAO), the production amount of apple in China was more than 40 million tons in 2015, which accounted for about half of the global production [Xiao et al., 2018]. Currently, apples are mostly consumed fresh and the processing markets only account for 33\% in China, which is extremely lower than above $70 \%$ in the developed countries; moreover, the intensively processed products are mainly the concentrated juice exported to the European and American markets [Bi et al., 2015]. There are some obvious problems such as simple processing production types, low processing rate as well as low value-added products in the postharvest processing of apples, which are restricting the healthy development of the apple industry in China.

Dried apples are rich in dietary fiber and bioactive components, and are convenient to handle, store, and utilize [Pasławska et al., 2017; Blanda et al., 2008]. They are a part

\footnotetext{
* Corresponding Author: E-mail: sxxds2008@163.com (Yingqiang Wang) science research and in commercial food products drying

of numerous prepared foods including snack preparations, integral breakfast foods, and so on [Vega-Gálvez et al., 2012]. In addition, drying fruits and vegetables into low water content provides new product formulas, such as fruits and vegetables crisps with unique texture and physical properties [Bi et al., 2016; Xiao et al., 2018; Velickova et al., 2014]. Furthermore, apple snacks play an important role in eating habits change, may substitute potato snacks and solve obesity problems among children or adults [Pasławska et al., 2017]. Therefore, apples dehydration process would be a promising path to deal with the problems as above mentioned.

The convective drying is still the most widely used drying method, which is applied to apples on the industrial production scale for its little capital, simple equipment and low energy input [Farias Aires et al., 2018; Velickova et al., 2014]. The main disadvantage of hot air drying is long drying time for exposure of the heat-sensitive materials to high temperature and aerobic environment, which may generate low quality dried products [Zhang et al., 2006]. Freeze drying (FD) under vacuum conditions is the best water removal method for all kinds of foods including apples, while it requires long drying time that would lead to high energy consumption and high capital investment. Therefore, FD is applied only with the high added-value products [Wang et al., 2018]. Microwave-vacuum drying (MVD) is increasingly used in food 
[Zhang et al., 2006]. Numerous studies have confirmed that MVD yields high-quality dehydrated products that are similar to or better than those dried by FD [Nimmanpipug et al., 2013; Chong et al., 2013]. Besides, MVD possesses advantages including shortened drying time, improved energy efficiencies, and reduced energy consumption [Zhang et al., 2006].

Pretreatments prior to drying are often used to reduce the initial moisture content, accelerate the drying process, improve quality of dried products, modify the physicochemical properties of dried material, and influence the heat and mass transfer during drying [Doymaz et al., 2010]. Some common pretreatments include blanching, osmotic dehydration, sulfite treatment or a combination of the above treatments [Camel et al., 2019; Wang et al., 2018; Doymaz et al., 2010]. The sulfiting at low concentration is the most commonly used pretreatment method for apples and other fruits for its features of simple operation and well preserved color of products. Due to chemical residues in the final product, which may cause asthmatic reactions in some sensitive individuals and other health problems, there is an increasing demand to produce sulfur-free dried fruits [Igual et al., 2012; Krokida et al., 2000]. Some novel pretreatments including ultrasound [Rodríguez et al., 2015; Nowacka et al., 2012; Mothibe et al., 2014], microwave [Zielinska et al., 2018; Mothibe et al., 2014; Liu et al., 2015], vacuum [Blanda et al., 2008], have been developed to satisfy the growing health-conscious consumers. Ultrasonic wave has been used to enhance mass transfer since it can create microscopic channels in solid material by unique mechanical fluctuation and cavitation effect [Rodríguez et al., 2015; Nowacka et al., 2012]. It is reported that ultrasonic wave pretreatment could reduce drying time by $10-30 \%$ [Zhao et al., 2017; Horuz et al., 2017]. Ultrasound pretreatment of apples resulted in dried products with greater rehydration ratios and softer texture due to disruption of the cell walls and would be preferred when dried fruits of low calories are required because of its high sugar loss [Nowacka et al., 2012; Mothibe et al., 2014].

In recent years, both pretreatments and drying methods of the apples have been widely studied in order to obtain high quality dehydrated apple products. However, little was known about the effects of different pretreatments on microwave vacuum drying kinetics, physicochemical properties and sensory quality of the apple slices. This study was aimed to compare the effects of five types of pretreatments (sulfite treatment (ST), osmotic dehydration treatment (OD), steam blanching (SB), steam blanching followed by osmotic dehydration (SB plus OD), and ultrasound treatment (UT)) on the drying kinetics, physicochemical properties, and sensory quality in microwave vacuum drying (MVD) apple slices.

\section{MATERIALS AND METHODS}

\section{Sample preparation}

The fresh Red Fuji apples used in this study were purchased from a local market in Qingyang (Gansu, China) and stored in a refrigerator at $4 \sim 8^{\circ} \mathrm{C}$ until the experiments were started.

Before each experiment, the apples were taken out and left to stand for $2 \mathrm{~h}$ in room to reach the environment tempera- ture. Then, the apples were washed, peeled, cored, and cut into half circular shape of $10 \mathrm{~mm}$ thickness using a multifunctional apple peeler (DM-6; Deming, BeJing, China), for further use.

\section{Pretreatments}

Five pretreatments were applied to the apple slices before drying and an untreated sample was used as control. The pretreatments used were sulfite treatment (ST), osmotic dehydration (OD), steam blanching (SB), steam blanching plus osmotic dehydration $(\mathrm{SB}+\mathrm{OD})$, and ultrasound treatment (UT). All the pretreatment experiments were conducted in duplicate and details of each treatment were described as follows:

Control: A batch of $200 \mathrm{~g}$ fresh apple slices without any pretreatment were used for drying.

Sulfite treatment (ST): A batch of $200 \mathrm{~g}$ apple slices was dipped in $2 \%$ sodium bisulfite solution for $2 \mathrm{~min}$, and then the surface water was removed using a filter paper prior to drying [Krokida et al., 2000].

Osmotic dehydration (OD): A batch of $200 \mathrm{~g}$ apple slices were immersed in $60^{\circ}$ Brix sucrose solution at $25^{\circ} \mathrm{C}$ for $180 \mathrm{~min}$. The ratio of material to liquid was $1: 8(\mathrm{w} / \mathrm{v})$ and a stirring was done with a glass rod every $30 \mathrm{~min}$. After the osmotic dehydration was finished, the samples were taken out and the surface sucrose solution was removed using a filter paper prior to drying [Nimmanpipug et al., 2013].

Steam blanching (SB): A batch of $200 \mathrm{~g}$ apples slices were leant on a stainless grid and blanched using $100^{\circ} \mathrm{C}$ steam for $180 \mathrm{~s}$. After blanching treatment, they were cooled with air and the surface water was removed before drying.

Steam blanching plus osmotic dehydration $(\mathrm{SB}+\mathrm{OD})$ : Apple slice samples of $200 \mathrm{~g}$ were blanching using $100^{\circ} \mathrm{C}$ steam for $180 \mathrm{~s}$ and then immersed in $60^{\circ}$ Brix sucrose solution for $180 \mathrm{~min}$. The other pretreated conditions were the same as the ones in the osmotic dehydration mentioned above. After the combined treatment, the samples were taken out and the surface sucrose solution was removed using a filter paper prior to drying.

Ultrasonic treatment (UT): According to a method described by Mothibe et al. [2014] with slight modifications, $200 \mathrm{~g}$ apple slices were immersed in distilled water and subjected to ultrasound waves for $10 \mathrm{~min}$ in an ultrasonic bath (KH-250DE; Kunshan Ultrasonic Instruments Ltd. Co., Kunshan, China). The water-to-fruit ratio was maintained at 4:1. The pretreatment was carried out at room temperature $\left(25^{\circ} \mathrm{C}\right)$. The ultrasonic frequency was $25 \mathrm{kHz}$ and the power was maintained at $200 \mathrm{~W}$, and no mechanical stirring was used in the ultrasonic process. After ultrasonic treatment, the apple slices were blotted with filter paper and used for drying.

\section{Microwave-vacuum drying (MVD)}

Both the non-pretreated and pretreated apple slices were dried in a lab-scale microwave-vacuum dryer (ORW1.2S-5Z; Orient Microwave Co., Ltd, Nanjing, China). The samples to be dried were arranged in a single layer on a tray and the microwave-vacuum dryer was operated at $5 \mathrm{kPa}$ (absolute pressure) and the power intensity for each drying test was $2.5 \mathrm{~W} / \mathrm{g}$ (of original mass $200 \mathrm{~g}$ of fresh sample). The temperature 
of the drying material to be dried was controlled at $50^{\circ} \mathrm{C}$ using an automatic on-off controller to avoid local charring. During the drying process, moisture loss was measured by periodically taking out using a digital balance (JH2102, Shanghai Precision \& Scientific Instrument Co. Ltd., China) with $0.01 \mathrm{~g}$ precision. Each periodical interval was $5 \mathrm{~min}$. After each weighing, the weight of the material and total drying time were recorded. The batch of weighed samples was abandoned and another batch of prepared original samples was dried until the next time interval. The samples were dehydrated until a moisture content of $0.76 \mathrm{~kg}$ water $/ \mathrm{kg}$ dry matter $(15 \%)$ was reached. Each drying experiment was conducted in triplicate. After the drying process was completed, the dried products were cooled down to room temperature and packed into a sealed polyethylene bag for further analyses.

\section{Calculation of drying rate and moisture ratio}

During MVD process, drying rate was determined as follows:

Drying rate $=\frac{X_{t}-X_{t+\Delta t}}{\Delta t}$

where: $X_{\mathrm{t}}, X_{\mathrm{t}+\Delta \mathrm{t}}$ was moisture content (kg water/kg dry matter) at time $t$ and $t+\Delta t$, respectively, $\Delta t$ was time interval (min).

The change of moisture content in time was defined as a dimensionless parameter and expressed as the following equation:

$M R=\frac{X-X_{e}}{X_{0}-X_{e}}$

where: $M R$ was the dimensionless moisture ratio, $X_{0}, X$ and $X_{\mathrm{e}}$ stood for the initial moisture content, the moisture content at time $t$ and the equilibrium moisture content, respectively. The parameter $t$ was the drying time (min). All results were expressed per dry basis (kg water/kg dry matter). The $M R$ can be simplified to $\frac{X}{X_{0}}$ instead of $\frac{X-X_{e}}{X_{0}-X_{e}}$ because of the value of dynamic equilibrium moisture content $X_{\mathrm{e}}$ which was very small in comparison with $X$ and $X_{0}$ [Kaya et al., 2007].

\section{Calculation of moisture diffusivity}

Drying process was proven to occur mostly in the falling rate period, and moisture transfer during drying was controlled by internal diffusion [Kaya et al., 2007]. The Fick's second diffusion law (Equation 3) had been widely used to describe the drying process in the falling rate period for most biological materials [Vega-Gálvez et al., 2012; Schoessler et al., 2012].

$$
\frac{\partial X}{\partial t}=D_{e f f} \frac{\partial^{2} X}{\partial x^{2}}
$$

where: $D_{\text {eff }}$ was the effective moisture diffusion coefficient $\left(\mathrm{m}^{2} / \mathrm{s}\right)$, which was a mass diffusion property of the product, and $x$ was the diffusion path $(\mathrm{m})$.
Assuming unidirectional and constant moisture diffusion, negligible shrinkage and temperature change during drying, analytical solutions of Equation 4 for an infinite slab geometry were expressed as Equation 4 [Crank, 1975]:

$$
\frac{X-X_{e}}{X_{0}-X_{e}}=\frac{8}{\pi^{2}} \sum_{n=0}^{\infty} \frac{1}{(2 n+1)^{2}} \cdot \exp \left(-\frac{(2 n+1)^{2} \pi^{2} \cdot D_{e f f}}{4 L^{2}} \cdot t\right)
$$

where: $L$ was the thickness of the apple slices (m).

For long drying periods, the first term of the series solution in Equation 4 can be used as stated in Equation 5.

$M R=\frac{8}{\pi^{2}} \exp \left(\frac{\pi^{2} \cdot D_{e f f}}{4 L^{2}} \cdot t\right)$

Equation 5 can be simplified to a straight-line equation as follows:

$\ln M R=\ln \left(\frac{8}{\pi^{2}}\right)-\frac{\pi^{2} \cdot D_{\text {eff }}}{4 L^{2}} \cdot t$

Plotting experimental drying data in terms of $\ln (M R)$ versus time, a straight line can be obtained, $D_{\text {eff }}$ were calculated according to the slop of the straight line.

\section{Moisture content determination}

Moisture was determined by oven drying (101-A; Kewei, Beijing, China) at $105^{\circ} \mathrm{C}$ to the constant weight [AOAC, 1995].

\section{Total sugar (TS) content determination}

Total sugar in fresh and dried apples was analyzed with the Fehling's method [GB/T 5009.7-2016]. Appropriate amount of ground sample (2.5-5.0 g) was put into a $250 \mathrm{~mL}$ volumetric flask. Next, $50 \mathrm{~mL}$ water, $5 \mathrm{~mL}$ zinc acetate solution $(219 \mathrm{~g} / \mathrm{L})$, and $5 \mathrm{~mL}$ potassium ferrocyanide solution $(106 \mathrm{~g} / \mathrm{L})$ were added to the sample, and then water was added to $250 \mathrm{~mL}$. The mixture was mixed well, stood for $30 \mathrm{~min}$, filtrated, and the clear filtrate was collected. The filtrate $(50 \mathrm{~mL})$ was absorbed and transferred to a $100 \mathrm{~mL}$ volumetric flask and $5 \mathrm{~mL} 50 \% \mathrm{HCl}$ were added. They were kept in a water bath at $70^{\circ} \mathrm{C}$ for $15 \mathrm{~min}$ and then neutralized with a sodium hydroxide solution $(200 \mathrm{~g} / \mathrm{L})$. The prepared solution was titrated with a calibrated Fehling g's solution. The assay was performed in triplicate. The results were expressed as $\mathrm{g}$ of glucose per $100 \mathrm{~g}$ of dry matter of sample.

\section{Titratable acidity (TA) determination}

Titratable acidity in fresh and dried apples was determined according to a titrimetric method [GB/T 12456-2008]. An appropriate amount of the sample (about $5 \mathrm{~g}$ ) was put in a mortar and the boiled water of the same weight as the sample was added, then the sample was grounded and transferred to a $250 \mathrm{~mL}$ volumetric flask with the boiled water having the temperature of $80^{\circ} \mathrm{C}$. The total amount of the sample and the water in the flask was controlled to about $150 \mathrm{~mL}$. After boiling for $30 \mathrm{~min}$ in a hot bath, the sample was cooled to room 
temperature, dilluted to $250 \mathrm{~mL}$, and then filtered. The filtrate $(20 \mathrm{~mL})$ was absorbed and transferred to a $250 \mathrm{~mL}$ Erlenmeyer flask. Distilled water $(40 \mathrm{~mL})$ and $1 \%$ phenolphthalein indicator $(0.2 \mathrm{~mL})$ were added to the flask, then titration was done with $0.01 \mathrm{M}$ or $0.05 \mathrm{M} \mathrm{NaOH}$. The assay was repeated twice. The results were expressed as g of malic acid equivalents per $100 \mathrm{~g}$ of dry matter of sample.

\section{Total phenolics content (TPC) determination}

A $3 \mathrm{~g}$ ground sample was extracted subsequently by a methanol:water solution acidified with $\mathrm{HCl}(50: 50 \mathrm{v} / \mathrm{v}, \mathrm{pH}$ $2,25 \mathrm{~mL} / \mathrm{g}$ sample) and an acetone:water solution $(70: 30 \mathrm{v} / \mathrm{v}$, $25 \mathrm{~mL} / \mathrm{g}$ sample) with continuous stirring at room temperature for $60 \mathrm{~min}$. The extracts were filtered through a Whatman No.1 filter paper, then the supernatants were combined and centrifuged at $3000 \times g$ for 15 min (TDL-40B; Anting, Shanghai, China) [Ovando-Martinez et al., 2009]. The total phenolics content was determined with the Folin-Ciocalteau reagent [Singleton et al., 1999]. The obtained supernatant $(0.5 \mathrm{~mL}$, diluted if necessary) was mixed with $0.5 \mathrm{~mL}$ of the Folin-Ciocalteu reagent in a $25 \mathrm{~mL}$ glass-stopped tube. After $3 \mathrm{~min}, 10 \mathrm{~mL}$ of a sodium carbonate solution $(75 \mathrm{~g} / \mathrm{L})$ were added and mixed. Additional distilled water $(14 \mathrm{~mL})$ was added up to make a final volume of $25 \mathrm{~mL}$, and then the sample was mixed thoroughly by inverting the tubes several times. After $1 \mathrm{~h}$, the absorbance at $750 \mathrm{~nm}$ was recorded with a spectrophotometer (751-UV-VIS; Shanghai analytical Instrument Factory, Shanghai, China). Gallic acid (Sigma Chemical Co., St. Louis, MO, USA) (0-50 mg/L) was used as a standard for the calibration curve. The tests were performed in triplicate. The total phenolics content was expressed as mg GAE per g of dry matter.

\section{Vitamin $C\left(V_{c}\right)$ content determination}

$L$-ascorbic acid content was determined by the 2,6-dichlorophenol-indophenol (Merck KGaA, Darmstadt, Germany) titrimetric method [GB/T 5009.86-2016]. A 5 g ground sample was transferred to a $100 \mathrm{~mL}$ volumetric flask with the oxalic acid solution $(20 \mathrm{~g} / \mathrm{L})$ and diluted to the scale. After shaking well and filtering, $10 \mathrm{~mL}$ filtrate was accurately absorbed and transferred to a $50 \mathrm{~mL}$ Erlenmeyer flask. Titration was done with the calibrated 2, 6-dichloroindophenol solution until the solution became pink and did not fade after 15 seconds, taking $10 \mathrm{~mL}$ oxalic acid solution as the control. All assays were done in triplicate; the vitamin $\mathrm{C}$ content was expressed as $\mathrm{mg} / 100 \mathrm{~g}$ dry matter.

\section{Color analysis}

A chroma meter CR-400 (Onica Minolta, Tokyo, Japan) calibrated with a white standard board was used to determine the color of sample surface. Readings were expressed in the CIE1976 $L^{*} a^{*} b^{*}$ scale, where $L^{*}$ meant lightness, with 100 being very white and 0 being dark; the $a^{*}$ value represented green $(-60)$ to red $(+60)$, and $b^{*}$ value represented blueness $(-60)$ to yellowness $(+60)$. The hue angle $\left(h^{\circ}\right)$, the chroma $\left(C^{*}\right)$, and the total color difference $(\Delta E)$ were calculated according to the values of $L^{*}, a^{*}$ and $b^{*}$ as follows:

$$
\begin{aligned}
& h^{\circ}=\operatorname{arctg}\left(b^{*} / a^{*}\right)\left(a^{*}>0, b^{*}>0\right) \\
& \text { or } h^{\circ}=180^{\circ}+\operatorname{arctg}\left(b^{*} / a^{*}\right)\left(a^{*}<0, b^{*}>0\right)
\end{aligned}
$$

$C^{*}=\sqrt{\left(a^{*}\right)^{2}+\left(b^{*}\right)^{2}}$

$\Delta E=\left[\left(L^{*}-L_{0}^{*}\right)^{2}+\left(a^{*}-a_{0}^{*}\right)^{2}+\left(b^{*}-b_{0}^{*}\right)^{2}\right]^{1 / 2}$

where: $L_{0}^{*}, a_{0}^{*}$ and $b_{0}^{*}$ were initial values of fresh apple slices; $L^{*}, a^{*}$, and $b^{*}$ were dried sample values. The $h^{\circ}$ revealed the color nuance; the values were defined as follows: redpurple: $0^{\circ}$, yellow: $90^{\circ}$, bluish-green: $180^{\circ}$, and blue: $270^{\circ}$. The $\mathrm{C}^{*}$ represented chromaticity and denoted the purity or the saturation of the color. The measurements were carried out with 5 slices for each treatment.

\section{Rehydration property analysis}

Rehydration property analysis was performed according to the method reported by Vega-Gálvez et al. [2012] with small modification. Two dried apple slices were rehydrated by soaking in $25^{\circ} \mathrm{C}$ distilled water. The samples were withdrawn from the flask at 30 min interval, drained on the filter paper and weighed. This step was repeated until the difference between two consecutive recordings was smaller than $0.001 \mathrm{~g}$. For all experiments, the solid-liquid ratio was kept at 1:50. The rehydration ratio $\left(R R_{\mathrm{t}}\right)$ was defined as the ratio of the mass of rehydrated samples to the mass of the sample and calculated as follows:

$R R_{t}=\frac{W_{t}}{W_{d}}$

where: $W_{\mathrm{d}}$ and $W_{\mathrm{t}}$ were the masses (g) of samples before rehydration and time $(t)$, respectively. Each experiment was conducted in triplicate and the results were expressed as the mean values.

\section{Shrinkage and density analysis}

The volume of both raw and dried slices was measured by the displacement method using toluene [Schoessler et al., 2012].

Five dried apple slices were randomly selected from each sample lot and weighed $\left(W_{1}\right)$ with the accuracy of $0.0001 \mathrm{~g}$. The slices were put into an empty $150 \mathrm{~mL}$ flask, filled up with toluene and weighed again $\left(W_{2}\right)$. The corresponding volume of dried samples $\left(V_{\mathrm{ds}}\right)$ was calculated as follows [Beigi, 2016]:

$V_{d s}=150-\frac{W_{2}-W_{1}}{\rho_{\text {toluene }}}$

The density of toluene $\left(\rho_{\text {toluene }}\right)$ is $0.87 \mathrm{~g} / \mathrm{mL}$ at $20^{\circ} \mathrm{C}$. After determination of the volume of dried slices, the shrinkage of the samples was calculated as follows:

$S \%=\left(1-\frac{V_{d s}}{V_{f s}}\right) \times 100$

where: $S$ - shrinkage $(\%), V_{\mathrm{ds}}$ - the final volume of dried apple slice $(\mathrm{mL})$, and $V_{\mathrm{fs}}$ - the volume of apple slice before drying $(\mathrm{mL})$.

The density $(\rho)$ of the dried material was calculated as follows: 
$\rho=\frac{m}{V}$

where: $m(\mathrm{~kg})$ was the mass of dried slices, and $V(\mathrm{~L})$ was the volume of dried slices. Five analyses were carried out for each test.

\section{Sensory evaluation}

A descriptive quantitative method was used to determine the sensory profile of the non-pretreated and pretreated dried apple slices. In this analysis, in order to understand the sensory attributes of the dried apple slices, which include color, texture, aroma, sweetness and sourness, a 15-number panel was trained with the fresh apple. The samples were evaluated in groups of 4 per session. They were coded with three digits and presented randomly. A categorized 20-point scale, anchored with "nothing" for number 1 and "very intense" for number 20, was used to measure attributed intensity [González-Herrera, et al., 2016]. In order to evaluate the preference of the non-pretreated and pretreated dried apple slices, the 15 panelists who frequently consume such products were asked to rate their liking of overall acceptability within a balanced nine-point hedonic rating where 9 denoted "like very much", 5 neither like nor dislike, and 1 indicated "dislike very much" [Velickova et al., 2014]. Three samples for each treatment were provided to each panelist; each sample consisted of five slices. All the prepared samples were coded with three-digit random numbers and presented in random order to the panelists.

\section{Statistical analysis}

Differences among mean values were estimated within an analysis of variance (ANOVA) with the application of Duncan's tests by SPSS 17.0.1. Mean values were considered significantly different when $\mathrm{p} \leq 0.05$.

\section{RESULTS AND DISCUSSIONS}

\section{Drying characteristics}

The original moisture content in the fresh apple sample was determined to be $89.8 \%$ (Table 1). The initial mois- ture contents of the apple slices submitted to ST, OD, SB, $\mathrm{SB}+\mathrm{OD}$, and UT were found to be $87.9 \%, 63.5 \%, 88.6 \%$, $68.8 \%$, and $88.7 \%$, respectively. As compared with the fresh sample, both $\mathrm{OD}$ and $\mathrm{SB}+\mathrm{OD}$ pretreatments resulted in a significantly lower moisture content of the apple slices due to osmotic dehydration in sugar liquid $(p<0.05)$.

Figure 1 revealed the variation of moisture content of the non-pretreated and pretreated apple slices with drying time during MVD. As shown in Figure 1, the moisture content decreased sharply at the initial drying stage and subsequently reduced slowly as the drying proceeded. In a relative short duration of less than $60 \mathrm{~min}$, all the apple samples were dehydrated to the desired moisture content of $0.17 \mathrm{~kg}$ water $/ \mathrm{kg}$ dry matter (d.m.) in the MVD. The total drying time was 45, 37, 40, 33, and $36 \mathrm{~min}$ for ST, OD, SB, SB+OD, and UT apple slices, respectively. The pretreatment had a significant influence on the total drying time and the various pretreatments used could reduce the drying time by $25-45 \%$. The SB+OD apple slices had the shortest drying time, which indicated that $\mathrm{SB}+\mathrm{OD}$ could reduce the drying time by $45 \%$ as compared with the one (about $60 \mathrm{~min}$ ) of the no-pretreated apple slices. The decrement in the total drying time was associated with the reduction in the original moisture content and the change in water transfer in the samples to be dried. Nowacka et al. [2012] reported that the drying time of apple slices dried by hot air after ultrasonic pretreatment was $31 \%$ shorter than that of untreated apple slices due to the appearance of microscopic channels within the fruit tissue structure. Dandamrongrak et al. [2002] found that the freezing and the combined blanching with freezing pretreatment were the most effective methods of improving the drying rate when drying banana because heating as well as freezing leads to cell disruption.

Drying rate, a function of drying time and moisture content, was a fundamental parameter that was computed from the drying data by estimating geometric derivation occurring in each consecutive time interval, and was expressed as $\mathrm{kg}$ water/(kg dry matter min). Figure 2 depicts the variation of drying rate with moisture content in the apple slices submitted to different treatments. The entire drying process in all the samples underwent a transient warm-up period at the beginning, followed by a falling rate period for a long

TABLE 1. Contents of moisture (\%), total sugar (TS), titratable acidity (TA), vitamin $\mathrm{C}\left(\mathrm{V}_{\mathrm{C}}\right)$, and total phenolics (TPC) in microwave-vacuum dried (MVD) apple slices subjected to different pretreatments.

\begin{tabular}{lcc|c|cc}
\hline Treatment & Moisture $(\%)$ & TS $(\mathrm{g} / 100 \mathrm{~g}$ dry matter $)$ & TA (g/100 g dry matter) & $\mathrm{V}_{\mathrm{C}}(\mathrm{mg} / 100 \mathrm{~g}$ dry matter) & TPC (mg/g dry matter) \\
\hline Fresh & $89.8 \pm 0.20^{\mathrm{a}}$ & $65.84 \pm 1.05^{\mathrm{c}}$ & $3.52 \pm 0.05^{\mathrm{a}}$ & $19.24 \pm 0.05^{\mathrm{a}}$ & $17.65 \pm 0.05^{\mathrm{a}}$ \\
Untreated & $15.3 \pm 0.11^{\mathrm{b}}$ & $63.85 \pm 2.16^{\mathrm{d}}$ & $3.21 \pm 0.16^{\mathrm{b}}$ & $8.56 \pm 0.16^{\mathrm{d}}$ & $9.90 \pm 0.06^{\mathrm{e}}$ \\
ST & $14.2 \pm 0.06^{\mathrm{c}}$ & $61.02 \pm 0.18^{\mathrm{e}}$ & $3.10 \pm 0.18^{\mathrm{bc}}$ & $12.74 \pm 0.18^{\mathrm{b}}$ & $12.98 \pm 0.07^{\mathrm{c}}$ \\
OD & $15.8 \pm 0.15^{\mathrm{b}}$ & $71.74 \pm 1.45^{\mathrm{b}}$ & $1.67 \pm 0.05^{\mathrm{f}}$ & $10.56 \pm 0.45^{\mathrm{c}}$ & $10.54 \pm 0.09^{\mathrm{de}}$ \\
SB & $13.7 \pm 0.15^{\mathrm{d}}$ & $62.89 \pm 3.25^{\mathrm{de}}$ & $2.93 \pm 0.25^{\mathrm{c}}$ & $6.89 \pm 0.25^{\mathrm{e}}$ & $18.37 \pm 0.08^{\mathrm{a}}$ \\
SB+OD & $14.2 \pm 0.21^{\mathrm{c}}$ & $77.90 \pm 2.25^{\mathrm{a}}$ & $1.72 \pm 0.15^{\mathrm{e}}$ & $5.91 \pm 0.45^{\mathrm{f}}$ & $14.21 \pm 0.10^{\mathrm{b}}$ \\
UT & $15.7 \pm 0.04^{\mathrm{b}}$ & $51.45 \pm 3.55^{\mathrm{f}}$ & $1.93 \pm 0.55^{\mathrm{d}}$ & $6.45 \pm 0.55^{\mathrm{e}}$ & $11.90 \pm 0.11^{\mathrm{d}}$ \\
\hline
\end{tabular}

Each value is expressed as mean value \pm standard derivation $(n=3)$. Different letters in the same column indicate significant differences at $p<0.05$. ST: sulfite treatment; OD: osmotic dehydration treatment; SB: steam blanching; SB+OD: steam blanching followed by osmotic dehydration; UT: ultrasound treatment. 
time. The drying rates in the falling rate stages of the drying process in the non-pretreated, ST, SB, and UT apple slices were quite high for high moisture content in the apple slices. It showed that drying rate decreased continuously as the moisture content decreased. There was no discernible constant rate period of drying in all samples, which suggested that the internal moisture diffusion played a decisive role in the drying process of apple slices and determined the drying characteristics of raw materials.

\section{Effective moisture diffusivity}

The graph of experimental values of $\ln (M R)$ of the apple slices against drying time was plotted, and the effective moisture diffusivity $\left(D_{\text {eff }}\right)$ of the apple slices was calculated according to Equation 6 and presented in Figure 3. The $D_{\text {eff }}$ values in MVD for ST, OD, SB, SB+OD, and UT were in the range of $1.64-3.46 \times 10^{-8} \mathrm{~m}^{2} / \mathrm{s}$, respectively. It was observed that the moisture diffusivity in the ST samples was significantly higher than in the control samples $(p<0.05)$, while the moisture diffusivities in the other pretreated samples were significantly lower than in the control samples $(p<0.05)$. The lowest value was found in the $\mathrm{SB}+\mathrm{OD}$ samples. The values of $D_{\text {eff }}$

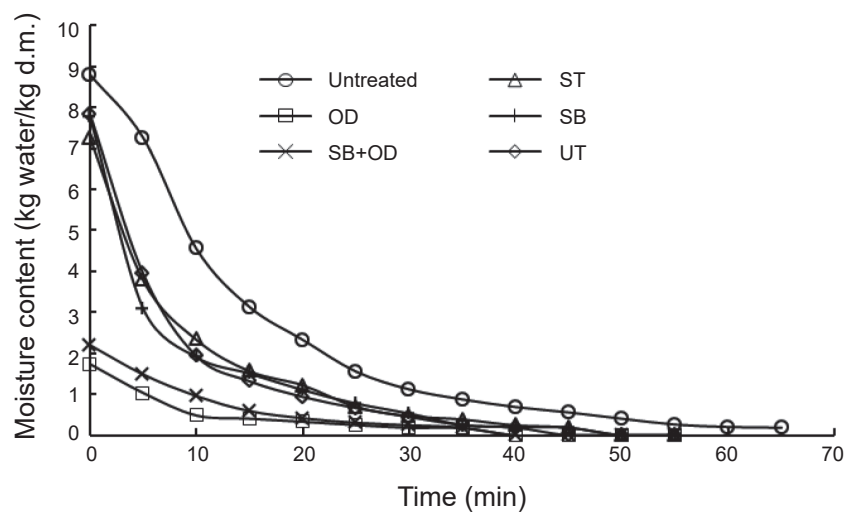

FIGURE 1. Microwave vacuum drying curves of apple slices as affected by different pretreatments. Note: ST: sulfite treatment; OD: osmotic dehydration treatment; $\mathrm{SB}$ : steam blanching; $\mathrm{SB}+\mathrm{OD}$ : steam blanching plus osmotic dehydration; UT: ultrasound treatment.

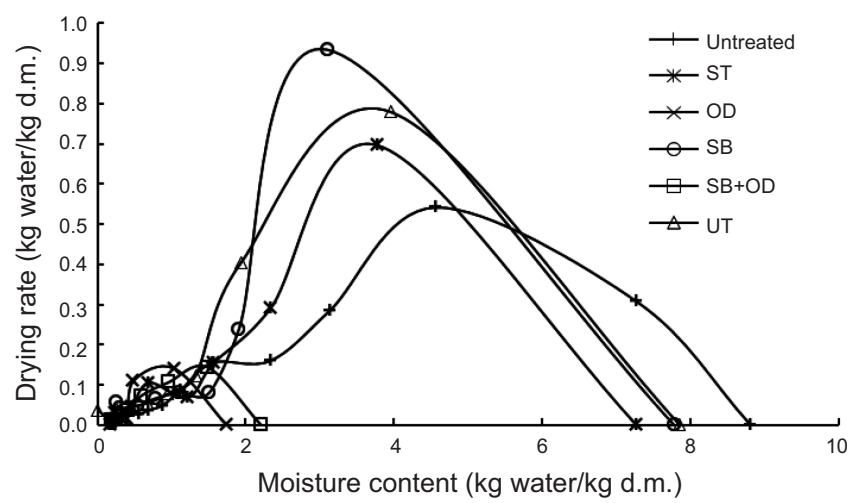

FIGURE 2. Microwave vacuum drying rate curves of apple slices as affected by different pretreatments. Note: ST: sulfite treatment; OD: osmotic dehydration treatment; SB: steam blanching; SB+OD: steam blanching followed by osmotic dehydration; UT: ultrasound treatment. obtained from this study were in range of $10^{-11}$ to $10^{-6} \mathrm{~m}^{2} / \mathrm{s}$ for food materials drying [Beigi, 2016]. The differences in the values may be caused by the differences in the initial moisture content, moisture state, and the cell disruption induced by different pretreatments.

\section{Chemical characterization}

The contents of chemical and bioactive components in the fresh, the non-pretreated, and pretreated dried apple slices were determined, and respective results were listed in Table 1. As shown in Table 1 , the contents of TS, TA, $V_{C}$, and TPC in fresh apple sample were $65.84 \mathrm{~g} / 100 \mathrm{~g}$ d.m., $3.52 \mathrm{~g} / 100 \mathrm{~g}$ d.m., $19.24 \mathrm{mg} / 100 \mathrm{~g}$ d.m., and $17.65 \mathrm{mg} / \mathrm{g} \mathrm{d.m.,}$ respectively. Pre-drying pretreatments used in this research strongly affected contents of the chemical and bioactive components in the dried products.

TS content in the dried samples ranged from $51.45 \mathrm{~g} / 100 \mathrm{~g}$ d.m. to $77.90 \mathrm{~g} / 100 \mathrm{~g} \mathrm{d.m}$. As expected, as compared with the fresh sample, both OD and SB+OD pretreatment led to an increase of $8.96-18.3 \%$ in TS content in the dried apple slices due to sugar uptake during OD, while lower TS content was observed in the non-pretreated, SB, UT, and ST pretreated dried apple slices. The highest TS content was observed in OD and SB+OD treatment $(71.74 \mathrm{~g} / 100 \mathrm{~g}$ d.m. and $77.90 \mathrm{~g} / 100 \mathrm{~g}$ d.m.) while UT samples had the lowest TS content $(51.45 \mathrm{~g} / 100 \mathrm{~g} \mathrm{~d}$.m.) because of sugar loss during ultrasound treatment process. Mothibe et al. [2014] found that ultrasound pretreatment resulted in a $24.7 \%$ loss of sugars of the apple cubes.

TA of the dried samples was in the range of 1.67 to $3.21 \mathrm{~g} / 100 \mathrm{~g} \mathrm{~d} . \mathrm{m}$. and the significant differences in the dried apple slices were also observed $(p<0.05)$. As compared with the fresh sample, MVD resulted in a decrease of $8.8-52.6 \%$ in TA content in all the dried products. The TA contents in the OD and SB+OD samples were lower than in the nopretreated and the other pretreated dried apple slices. The lowest value was observed in OD samples while the highest value was observed in ST samples. Pasławska et al. [2017] and Kowalska et al. [2018] reported similar phenomenon of TA value decrease after fruit immersion in a sugar solution.

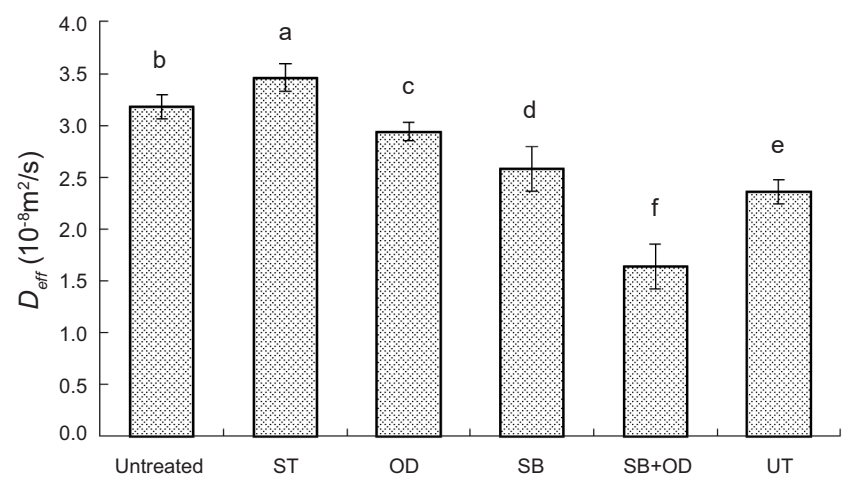

FIGURE 3. Effective moisture diffusion coefficient of dehydrated apple slices as affected by different pretreatments. Note: ST: sulfite treatment; OD: osmotic dehydration treatment; SB: steam blanching; SB+OD: steam blanching plus osmotic dehydration; UT: ultrasound treatment. Different letters indicate a significant difference $(p \leq 0.05)$. 
The changes in TA may be attributed to the elution of organic acids from tissue during OD process [Kowalska et al., 2018].

Ascorbic acid and phenolics are important nutritional or bioactive compounds in apples, and these chemicals are wellknown antioxidants that play an important role in promoting health [Loncaric et al., 2014; Blanda et al., 2008]. As expected, drying treatment had an adverse effect on the content of $V_{C}$ and TPC in all the dried samples. As compared with the fresh apples, MVD resulted in a decrease of 33.8-69.3\% in ascorbic acid content in all dried products. The ascorbic acid content in the OD and ST samples was significantly higher than in the non-pretreated sample and the opposite tendency was observed in the $\mathrm{SB}, \mathrm{SB}+\mathrm{OD}$, and UT samples. The loss in $\mathrm{V}_{\mathrm{C}}$ was attributed to the thermal disruption and leakage of water-soluble $\mathrm{V}_{\mathrm{C}}$ during pretreatment [Wang et al., 2018; Horuz et al., 2017]. However, it was reported that the presence of sugar would stabilize vitamin $\mathrm{C}$ in fruits [Pasławska et al., 2017].

With regard to the total phenolics, MVD resulted in a significant decrease (19.5-43.9\%) in the total phenolics content in all the other dried products as compared with the fresh sample $(p<0.05)$ except for a slight increase of $4 \%$ in the SB-pretreated samples. Moreover, the total phenolics content in the pretreated dried products was significantly or slightly higher than in the non-pretreated samples depending on which pretreated method was used. The highest TPC value was observed in the SB-treated samples (18.37 mg/g d.m.) followed by the SB+OD samples (14.21 mg/g d.m.), then followed by the ST samples $(12.98 \mathrm{mg} / \mathrm{g} \mathrm{d.m}$.). The TPCs of OD and UT samples were comparable and were the lowest one (about $11 \mathrm{mg} / \mathrm{g} \mathrm{d} . \mathrm{m}$.) due to the increment in dry matter induced by the leaching process. Processing including soaking, osmosis, heating and drying, may lead to the loss of phenolics in the food systems due to the leaching process, thermal degradation and the dilution effect [Mejia-Meza et al., 2010; Khandelwal et al., 2010]. At the same time, the amount of non-extractable phenolics was almost double of the extractable phenolics in the plant, and these non-extractable phenolics may release from the tissue in acid and high temperature environment as well as upon long-term ultrasonic treatment, which could cause an increase of phenolics con- tent in the dried samples [Faller \& Fialho, 2010; Horuz et al., 2017]. Additionally, sugar addition before processing was found to reduce phenolics loss in frozen and freeze-dried apple purée [Loncaric et al., 2014]. Obviously, the differences in the total phenolics content of the dried samples are ascribed to the multiple factors as mentioned above.

\section{Color}

Color is an important quality attribute of dried foods, which is the first parameter customers use to judge the quality of dried products [Chong et al., 2013]. Desirable dried products are the closest to the fresh fruit in color. The color parameters including $L^{*}, a^{*}, b^{*}, C^{*}, \Delta E$ and $\mathrm{h}^{\mathrm{O}}$ of both the fresh and the dried apple samples were determined and the results were listed in Table 2. Both drying and pretreatments applied in this research greatly changed the original color of the flesh in fresh apples. As compared with the fresh samples, dehydration resulted in a significant decrease in the $L^{*}$ and $h^{\text {o values }}$ and a significant increase in $a^{*}, b^{*}$, and $C^{*}$ values in the nonpretreated and pretreated dried apple slices $(p<0.05)$. The $\Delta \mathrm{E}$ values of all the dried samples were in the range from 2.82 to 27.64 , and the non-pretreated sample had the greatest $\Delta \mathrm{E}$ value, followed by the UT and OD samples; the lowest $\Delta \mathrm{E}$ value was observed in the ST dried products. Obviously, the pretreatment prior to drying inhibited these changes in color to a different extent. It is noteworthy that the individual value of color parameter for the ST apples slices was closer to that of the fresh samples, followed by SB and SB+OD samples. The most remarkable change in color was observed in the dried product submitted to OD and UT, indicating that the severe browning occurred in both of them. The browning in fruits may commonly attribute to the oxidation of phenolics and to caramelization [Rodríguez et al., 2015; Nimmanpipug et al., 2013]. Various methods including lowering $\mathrm{pH}$, applying citric acid as a metal chelator, and avoiding exposure to oxygen have been studied for inhibiting PPO or slowing the browning reaction, and the sulfur dioxide treatment is still the most effective method and has been widely used in the food industry [Krokida et al., 2000; Igual et al., 2012].

The $h^{\circ}$ of the fresh sample was about $92.08^{\circ}$, while those of all the dried samples were in the range of $68^{\circ}-89^{\circ}$, which

TABLE 2. Effect of different pretreatments on the color parameters of microwave-vacuum dried (MVD) apple slices.

\begin{tabular}{l|c|c|c|c|c|c}
\hline Treatment & $\mathrm{L}^{*}$ & $\mathrm{a}^{*}$ & $\mathrm{~b}^{*}$ & $\Delta E$ & $\mathrm{C}^{*}$ & $\mathrm{~h}^{\mathrm{o}}$ \\
\hline Fresh & $70.84 \pm 0.06^{\mathrm{a}}$ & $-0.56 \pm 0.12^{\mathrm{g}}$ & $15.08 \pm 0.15^{\mathrm{d}}$ & - & $15.09 \pm 0.15^{\mathrm{e}}$ & $92.08 \pm 0.13^{\mathrm{a}}$ \\
Untreated & $45.34 \pm 1.09^{\mathrm{f}}$ & $8.22 \pm 0.18^{\mathrm{a}}$ & $21.12 \pm 0.35^{\mathrm{a}}$ & $27.64 \pm 0.16^{\mathrm{a}}$ & $22.66 \pm 0.34^{\mathrm{a}}$ & $68.77 \pm 0.12^{\mathrm{g}}$ \\
ST & $68.34 \pm 1.08^{\mathrm{b}}$ & $0.23 \pm 0.15^{\mathrm{f}}$ & $16.12 \pm 0.25^{\mathrm{c}}$ & $2.82 \pm 0.14^{\mathrm{f}}$ & $16.12 \pm 0.15^{\mathrm{d}}$ & $89.23 \pm 0.05^{\mathrm{b}}$ \\
OD & $52.91 \pm 1.21^{\mathrm{e}}$ & $4.46 \pm 0.19^{\mathrm{b}}$ & $15.58 \pm 0.18^{\mathrm{d}}$ & $18.63 \pm 0.21^{\mathrm{c}}$ & $16.21 \pm 0.25^{\mathrm{d}}$ & $74.06 \pm 0.35^{\mathrm{f}}$ \\
SB & $57.84 \pm 0.6^{\mathrm{d}}$ & $2.49 \pm 0.12^{\mathrm{d}}$ & $18.07 \pm 0.15^{\mathrm{b}}$ & $13.68 \pm 0.12^{\mathrm{d}}$ & $18.24 \pm 0.31^{\mathrm{c}}$ & $82.20 \pm 0.25^{\mathrm{d}}$ \\
SB+OD & $60.56 \pm 1.01^{\mathrm{c}}$ & $1.71 \pm 0.11^{\mathrm{e}}$ & $17.57 \pm 0.35^{\mathrm{bc}}$ & $10.82 \pm 0.05^{\mathrm{e}}$ & $17.65 \pm 0.25^{\mathrm{cd}}$ & $84.48 \pm 0.15^{\mathrm{c}}$ \\
UT & $53.56 \pm 1.01^{\mathrm{e}}$ & $3.71 \pm 0.21^{\mathrm{c}}$ & $20.17 \pm 0.29^{\mathrm{a}}$ & $21.79 \pm 0.11^{\mathrm{b}}$ & $20.51 \pm 0.09^{\mathrm{b}}$ & $79.63 \pm 0.23^{\mathrm{e}}$ \\
\hline
\end{tabular}

Each value is expressed as mean value \pm standard derivation $(n=3)$. Different letters in the same column indicate significant differences at $p<0.05$. ST: sulfite treatment; OD: osmotic dehydration treatment; SB: steam blanching; SB+OD: steam blanching followed by osmotic dehydration; UT: ultrasound treatment. $L^{*}$ : white 100 to 0 dark; $a^{*}$ : green $(-60)$ to red $(+60) ; b^{*}$ : blueness $(-60)$ to yellowness $(+60) ; h^{0}:$ hue angle; $C^{*}$ : chroma; $\Delta E$ : total color difference. 
represented an early yellow nuance. The ST products provided the highest $h^{\mathrm{o}}$ value, followed by the $\mathrm{SB}+\mathrm{OD}$ and $\mathrm{SB}$ products. The lowest $h^{\mathrm{o}}$ value was observed in the non-pretreated dried products.

\section{Rehydration characteristics}

Rehydration is a determination of damage to the material caused by drying process. Additionally, most dehydrated products need to be rehydrated before usage; a rapid and complete rehydration is needed when immersion in water is desirable. Figure 4 presents the variation of the rehydration ratio versus time for the non-pretreated and pretreated dried apple slices during rehydration. The rehydrated rate sharply increased with rehydration time in the initial rehydration stage, then gradually decreased to zero; the high rate of the water uptake at the beginning stage can be explained by the capillaries and cavities near the material surface, which are rapidly filled up with water [Horuz et al., 2017].

The rehydration rate of dehydrated apple slices treated by $\mathrm{SB}$ was the fastest, followed by UT, ST, $\mathrm{SB}+\mathrm{OD}$, and $\mathrm{OD}$

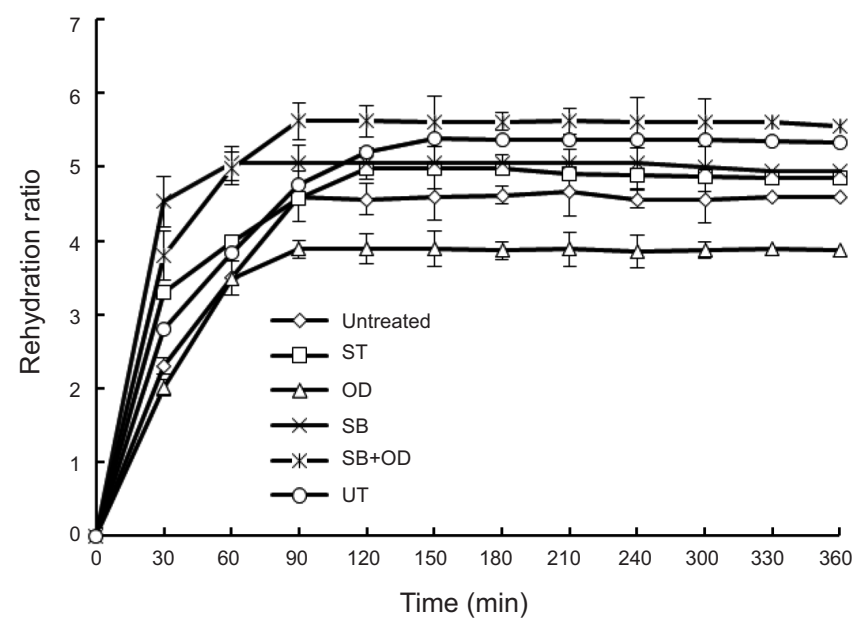

FIGURE 4. Effect of different pretreatments on the rehydration ratio of dried apple slices. Note: ST: sulfite treatment; OD: osmotic dehydration treatment; SB: steam blanching; SB+OD: steam blanching followed by osmotic dehydration; UT: ultrasound treatment.

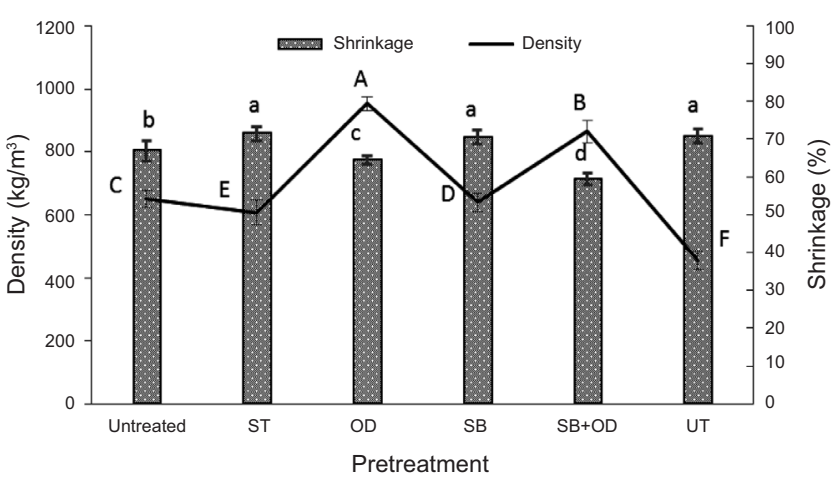

FIGURE 5. Effect of different pretreatments on shrinkage and density of dried apple slices. Note: ST: sulfite treatment; OD: osmotic dehydration treatment; SB: steam blanching; SB+OD: steam blanching followed by osmotic dehydration; UT: ultrasound treatment. Different letters indicate a significant difference $(p \leq 0.05)$ in the same legend. samples, while the rehydration rate of untreated dried products was the slowest. The stabilized rehydration ratio for $\mathrm{SB}$, $\mathrm{OD}, \mathrm{SB}+\mathrm{OD}$, untreated groups, ST and UT was 5.05, 3.89, 5.62 and $4.6,4.98$ and 5.38, respectively. The apple slices pretreated by $\mathrm{SB}+\mathrm{OD}$ had the highest rehydration ratio. Ultrasound and thermal treatments destroyed the structure of the material to be dried, and formed many micro-channels on the surface of the material, thus resulting in faster rehydration rate but lower rehydration ratio during drying [Vega-Gálvez et al., 2012; Horuz et al., 2017].

\section{Shrinkage and density}

Figure 5 presents the shrinkage and apparent density of the non-pretreated and pretreated dried apple slices. Compared with the non-pretreated samples, the three pretreatments including ST, SB and UT increased the shrinkage of the samples while the other two pretreatments, i.e. $\mathrm{OD}$ and $\mathrm{SB}+\mathrm{OD}$, contributed to shrinkage decrease. There were no significant differences among the ST, SB and UT in shrinkage percent $(p>0.05)$, and their shrinkage was about $70 \%$, which was significantly higher than the one in the nonpretreated samples $(p<0.05)$. The dried samples pretreated by OD had the lowest shrinkage percent (59.5\%) followed by the $\mathrm{SB}+\mathrm{OD}$ pretreated samples, which was significantly lower than the one in the non-pretreated samples $(p<0.05)$. It was reported that shrinkage was associated with the moisture content of the samples to be dried during MVD. When moisture was removed from tissues, a pressure imbalance was created between the inside and outside of the tissue, which may generate compressive stress and lead to shrinkage [Nahimana \& Zhang, 2011].

The apparent density of the non-pretreated and pretreated dried apple slices was found out in the range of $455-$ $-953 \mathrm{~kg} / \mathrm{m}^{3}$ and the pretreatment methods had a significant influence on the apparent density of the dried samples $(p<0.05)$. The apparent density of the non-pretreated dried sample was $652 \mathrm{~kg} / \mathrm{m}^{3}$, which was significantly higher than in the dried samples pretreated by UT, ST and SB, but lower than in the dried samples pretreated by $\mathrm{OD}$ and $\mathrm{SB}+\mathrm{OD}$ $(p<0.05)$. The dried samples pretreated by $\mathrm{OD}$ and $\mathrm{SB}+\mathrm{OD}$ obtained a relatively higher apparent density while the dried samples pretreated by UT had the lowest value of this parameter due to their lower shrinkage and sugar loss [Nowacka et al., 2012; Mothibe et al., 2014].

\section{Sensory evaluation}

The results of sensory evaluation for the non-pretreated and pretreated dried apple slices are listed in Table 3. It revealed that the pretreatment had a significant influence on sweetness, texture, aroma, sourness, color, and over acceptability of apple slices $(p<0.05)$. The dried apple slices pretreated by ST had the best color, but the poorest aroma. Both OD and UT pretreatments were the best with regard to maintaining the original aroma of the fresh apple in the dried apple slices which also had a softer texture. The dried samples submitted to SB+OD and OD had a harder texture, were more sweet, and had weaker sourness than the other samples. As for the overall acceptability, the five selected pretreatments could improve the sensory quality of the dried apple slices 
TABLE 3. Effect of different pretreatments on sensory qualities of microwave-vacuum dried (MVD) apple slices.

\begin{tabular}{l|c|c|c|c|c|c}
\hline Treatment & Sweetness & Texture & Aroma & Sourness & Color & Overall acceptability \\
\hline Untreated & $10.8 \pm 0.9^{\mathrm{c}}$ & $15.4 \pm 0.8^{\mathrm{c}}$ & $16.3 \pm 1.2^{\mathrm{a}}$ & $14.7 \pm 0.7^{\mathrm{a}}$ & $8.3 \pm 0.7^{\mathrm{e}}$ & $5.6 \pm 0.9^{\mathrm{e}}$ \\
ST & $10.3 \pm 0.9^{\mathrm{c}}$ & $14.3 \pm 0.7^{\mathrm{d}}$ & $12.7 \pm 0.6^{\mathrm{c}}$ & $14.6 \pm 0.4^{\mathrm{a}}$ & $19.3 \pm 1.1^{\mathrm{a}}$ & $6.1 \pm 1.7^{\mathrm{d}}$ \\
OD & $18.3 \pm 1.1^{\mathrm{a}}$ & $19.1 \pm 0.9^{\mathrm{a}}$ & $15.7 \pm 0.7^{\mathrm{a}}$ & $5.3^{\mathrm{a}} \pm 0.7^{\mathrm{d}}$ & $10.9 \pm 0.3^{\mathrm{d}}$ & $5.5 \pm 0.8^{\mathrm{e}}$ \\
SB & $12.2 \pm 0.6^{\mathrm{b}}$ & $14.9 \pm 0.7^{\mathrm{cd}}$ & $14.2 \pm 0.8^{\mathrm{b}}$ & $12.9 \pm 1.5^{\mathrm{b}}$ & $13.2 \pm 0.6^{\mathrm{c}}$ & $8.1 \pm 1.2^{\mathrm{a}}$ \\
SB+OD & $19.0 \pm 0.7^{\mathrm{a}}$ & $16.9 \pm 1.1^{\mathrm{b}}$ & $14.5 \pm 0.4^{\mathrm{b}}$ & $4.9 \pm 0.7^{\mathrm{d}}$ & $16.5 \pm 0.7^{\mathrm{b}}$ & $7.6 \pm 2.5^{\mathrm{b}}$ \\
UT & $7.9 \pm 0.8^{\mathrm{d}}$ & $11.2 \pm 0.7^{\mathrm{e}}$ & $15.8 \pm 0.7^{\mathrm{a}}$ & $6.8 \pm 0.9^{\mathrm{c}}$ & $13.9 \pm 0.8^{\mathrm{c}}$ & $7.1 \pm 2.7^{\mathrm{c}}$ \\
\hline
\end{tabular}

The results are mean \pm standard deviation $(n=3)$.Values with different superscript letters in the same column are significantly different $(\mathrm{p}<0.05)$. ST: sulfite treatment; OD: osmotic treatment; SB: steam blanching; SB+OD: steam blanching followed by osmotic dehydration; UT: ultrasound treatment.

in comparison with the non-pretreated samples to a different extent. The overall acceptability score of the dried apple products submitted to different pretreatments was decreased in the following order: $\mathrm{SB}>\mathrm{SB}+\mathrm{OD}>\mathrm{UT}>\mathrm{ST}>\mathrm{OD}$.

\section{CONCLUSION}

Based on the results of the present investigation, we concluded that the pretreatments applied had a profound influence on the microwave vacuum kinetics and the quality of the dehydrated apple products. Five selected pretreatments could shorten the microwave vacuum drying time of the apple slices, and the effective moisture diffusivity $\left(D_{e f f}\right)$ ranged from $1.64 \times 10^{-8}$ to $3.46 \times 10^{-8} \mathrm{~m}^{2} / \mathrm{s}$ under different pretreatment conditions. As compared with the non-pretreated dried apple slices, different pretreatments significantly changed contents of the chemical and bioactive components and improved sensory quality of the dried apple products in a specific way. With the enhancement of consumers' health awareness, non-sulfur pretreatments including SB, OD, UT as well as their combinations are recommended in producing the dried apples. The selection of a reasonable pretreatment method prior to drying depends on the different specific demand and the investment cost of the industry. For example, the advantages of the sulfur-related pretreatment include a relatively low production cost and a cheap product price; while the ultrasound pretreatment would be preferred when dried fruits of low calories are required since it results in a high sugar loss.

\section{FUNDING}

The authors gratefully acknowledged the financial supports provided by the National Natural Science Foundation of China (No. 31460398) and the Scientific Research Starting Foundation for Doctor of Longdong University(No: 2014XYBY11).

\section{CONFLICT OF INTERESTS}

The author(s) declared no potential conflicts of interest with respect to the research, authorship, and/or publication of this article.

\section{REFERENCES}

1. AOAC. 1995. Official Methods of Analysis of the Association of Official Analytical Chemists. $16^{\text {th }}$ ed. Washington, DC.

2. Beigi, M. (2016). Hot air drying of apple slices: Dehydration characteristics and quality assessment. Heat and Mass Transfer, 52(8), 1435-1442.

3. Bi, J.F., Yang, A.J., Liu, Y.X., Wu, X.Y., Chen, Q.Q.,Wang, Q., Lv, J., Wang, X. (2015). Effects of pretreatments on explosion puffing drying kinetics of apple chips. LWT - Food Science and Technology, 60(2), 1136-1142.

4. Blanda, G., Cerretani, L., Bendini, A., Cardinali, A., Scarpellini, A., Lercker, G. (2008). Effect of vacuum impregnation on the phenolic content of Granny Smith and Stark Delicious frozen apple cvv. European Food Research and Technology, 226(5), 1229-1237.

5. Camel, L., Jiang, N., Song, J.F., Ling, D.J., Liu, C.Q., Huang, J.P., Wei, Q.Y., Zhang, M. (2019). Effects of pretreatments on properties of microwave vacuum drying of sweet potato slices. Drying Technology, DOI: 10.1080/07373937.2018.1543702.

6. Chong, C.H., Law, C.L., Figiel, A., Wojdyło, A., Oziembłowski, M. (2013). Colour, phenolic content and antioxidant capacity of some fruits dehydrated by a combination of different methods. Food Chemistry, 141(4), 3889-3896.

7. Crank, J. (1975). The Mathematics of Diffusion. 2nd ed. London: Oxford University Press.

8. Dandamrongrak, R., Young, G.., Mason, R. (2002). Evaluation of various pre-treatments for the dehydration of banana and selection of suitable drying models. Journal of Food Engineering, 55(2), 139-146.

9. de Farias Aires, J.E., da Silva, W.P.,D., de Farias Aires, K.L.C., da Silva Júnior, A.F., da Silva, C.M.D.P. (2018). Convective drying of osmo-dehydrated apple slices: Kinetics and spatial behavior of effective mass diffusivity and moisture content. Heat and Mass Transfer, 54(4), 1121-1134.

10. Doymaz, İ. (2010). Effect of citric acid and blanching pre-treatments on drying and rehydration of Amasya red apples. Food Bioproducts and Processing, 88(2-3), 124-132.

11. Faller, A.L.K., Fialho, E. (2010). Polyphenol content and antioxidant capacity in organic and conventional plant foods. Journal of Food Composition and Analysis, 23(6), 561-568.

12. GB/T 12456-2008. Determination of total acid in foods. National Standard of the People's Republic of China. Beijing. 
13. GB/T 5009.7-2016. Determination of reducing sugar in foods. China National Standard for food safety. Beijing.

14. GB/T5009.86-2016. Determination of ascorbic acid in food. China National Standard for food safety. Beijing, China.

15. González-Herrera, S.M., Rutiaga-Quinones, O.M., Aguilar, C.N., Ochoa-Martínez, L.A., Contreras-Esquivel, J.C., Lopez, M.G., Rodríguez-Herrera, R. (2016). Dehydrated apple matrix supplemented with agave fructans, inulin, and oligo fructose. LWT - Food Science Technology, 65, 1059-1065.

16. Horuz, E., Jaafar, H.J., Maskan, M. (2017). Ultrasonication as pretreatment for drying of tomato slices in a hot air-microwave hybrid oven. Drying Technology, 35(7), 849-859.

17. Igual, M.., Garcia-Martinez, M.., Martin-Esparza, M.E., Martinez-Navarette, N. (2012). Effect of processing on the drying kinetics and functional value of dried apricot. Food Research International, 47(2), 284-290

18. Kaya, A., Aydin, O., Demirtas, C., Akgün, M. (2007). An experimental study on the drying kinetics of quince. Desalination, 212(1-3), 328-343.

19. Khandelwal, S., Udipi, S.A., Ghugre, P. (2010). Polyphenols and tannins in Indian pulses: effect of soaking, germination and pressure cooking. Food Research International, 43(2), 526-530 .

20. Kowalska, H., Marzec, A., Kowalska, J., Samborska, K., Tywonek, M., Lenart, A. (2018). Development of apple chips technology. Heat and Mass Transfer, 54(12), 3573-3586.

21. Krokida, M.K., Kiranoudis, C.T., Maroulis, Z.B., Marinos-Kouris, D. (2000). Effect of pretreatment on color of dehydrated products. Drying Technology, 18(6), 1239-1250.

22. Liu, P., Mujumdar, A.S., Zhang, M., Jiang, H. (2015). Comparison of three blanching treatments on the color and anthocyanin level of the microwave-assisted spouted bed drying of purple flesh sweet potato. Drying Technology, 33(1), 66-71.

23. Loncaric, A., Dugalic K., Mihaljevic, I., Jakobek, L., Pilizota, V. (2014). Effects of sugar addition on total polyphenol content and antioxidant activity of frozen and freeze-dried apple purée. Journal of Agricultural and Food Chemistry, 62 (7), 1674-1682.

24. Mejia-Meza, E.I., Yáñez, J.A., Remsberg, C.M., Takemoto, J.K., Davies, N.M., Rasco, B., Clary, C. (2010). Effect of dehydration on raspberries: polyphenol and anthocyanin retention, antioxidant capacity, and antiadipogenic activity. Journal of Food Science, 75(1), H5-H12.

25. Mothibe, K. J., Zhang, M., Mujumdar, A. S., Wang, Y. C., Cheng, X. (2014). Effects of ultrasound and microwave pretreatments of apple before spouted bed drying on rate of dehydration and physical properties. Drying Technology, 32(15),1848-1856.

26. Nahimana, H., Zhang, M. (2011). Shrinkage and color change during microwave vacuum drying of carrot. Drying Technology, 29(7), 836-847.

27. Nimmanpipug, N., Therdthai, N., Dhamvithee, P. (2013). Characterization of osmotically dehydrated papaya with further hot air drying and microwave vacuum drying. International Journal of Food Science \& Technology, 48(6), 1193-1200.

28. Nowacka, M., Wiktor, A., Sledz, M., Jurek, N., Witrowa-Rajchert, D. (2012). Drying of ultrasound pretreated apple and its selected physical properties. Journal of Food Engineering, 113(3), $427-433$.
29. Ovando-Martinez, M., Sáyago-Ayerdi, S., Agama-Acevedo, E., Goñi, I., Bello-Pérez, L.A. (2009). Unripe banana flour as an ingredient to increase the undigestible carbohydrates of pasta. Food Chemistry, 113(1), 121-126.

30. Pasławska, M., Stępień, B., Nawirska-Olszańska, A., Maślankowski, R., Rydzak, L. (2017). Effect of vacuum impregnation on drying kinetics and selected quality factors of apple cubes. International Journal of Food Engineering, 13(6), art. no. 20160309.

31. Rodríguez, O., Llabrés, P.J., Simal, S., Femenia, A., Rosselló, C. (2015). Intensification of predrying treatments by means of ultrasonic assistance: Effects on water mobility, PPO activity, microstructure, and drying kinetics of apple. Food and Bioprocess Technology, 8(3), 503-515.

32. Schoessler, K., Jaeger, H., Knorr, D. (2012). Effect of continuous and intermittent ultrasound on drying time and effective diffusivity during convective drying of apple and red bell pepper. Journal of Food Engineering, 108(1), 103-110.

33. Singleton, V.L., Orthofer, R., Ramuela-Raventos, R.M. (1999). Analysis of total phenols and other oxidation substrates and antioxidants by means of Folin-Ciocalteu reagent. Oxidants and Antioxidants, Part A, 299(1), 152-178.

34. Vega-Gálvez, A., Ah-Hen, K., Chacana, M., Vergara, J., Martinez-Monzo, J., Garcia-Segovia, P., Lemus-Mondaca, R., Di Scala, K. (2012). Effect of temperature and air velocity on drying kinetics, antioxidant capacity, total phenolic content, colour, texture and microstructure of apple (var. Granny Smith) slices. Food Chemistry, 132(1), 51-59.

35. Velickova, E., Winkelhausen, E., Kuzmanova, S. (2014). Physical and sensory properties of ready to eat apple chips produced by osmo-convective drying. Journal of Food Science and Technology, 51(12), 3691-3701.

36. Wang, H.O., Fu, Q.Q., Chen, S.J. (2018). Effect of hot-water blanching pretreatment on drying characteristics and product qualities for the novel integrated freeze-drying of apple slices. Journal of Food Quality, 2018(5), 1-12.

37. Xiao, M., Bi, J.F., Yi, J.Y., Zhao, Y., Peng, J., Zhou, L., Chen, Q. (2018). Osmotic pretreatment for instant controlled pressure drop dried apple chips: Impact of the type of saccharides and treatment conditions. Drying Technology, 37(7), 896-905.

38. Zhang, M., Tang, J., Mujumdar, A.S., Wang, S. (2006). Trends in microwave related drying of fruits and vegetables. Trends in Food Science and Technology, 17(10), 524-534.

39. Zhao, Y., Wang, W., Zheng, B., Zheng, B.D., Miao, S., Tian, Y.T. (2017). Mathematical modeling and influence of ultrasonic pretreatment on microwave vacuum drying kinetics of Lotus (Nelumbo Nucifera Gaertn.) seeds. Drying Technology, 35(5), 553-563.

40. Zielinska, M., Zielinska, D., Markowski, M. (2018). The effect of microwave-vacuum pretreatment on the drying kinetics, color and the content of bioactive compounds in osmo-microwavevacuum dried cranberries (Vaccinium Macrocarpon). Food Bioprocess and Technology, 11 (3), 585-602.

Submitted: 24 March 2019. Revised: 1 July 2019. Accepted 16 July 2019. Published on-line: 21 August 2019. 